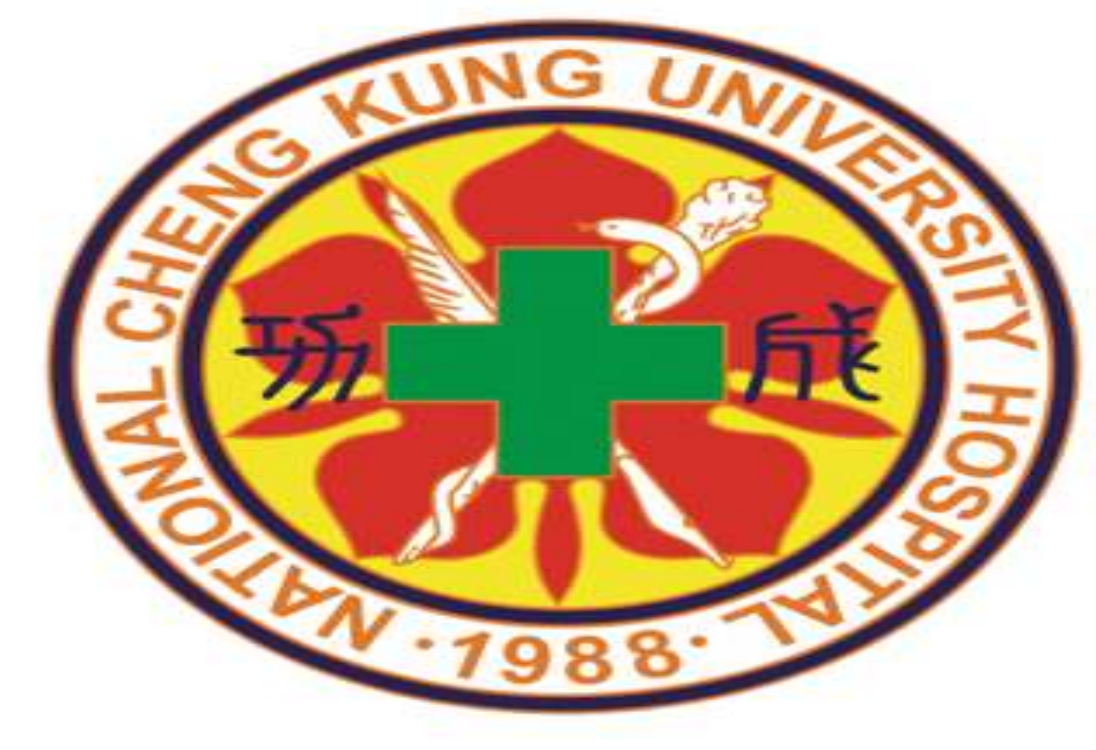

\title{
Intubation Difficulty Scale and Time in Clinical Practice
}

\author{
Hao-Hsun, Chang MD ${ }^{1}$, Jung-Der Wang MD, Sc. $D^{2}$, Hsun-Chang Shih, MD ${ }^{3}$, Ting-Wei Kang MD ${ }^{1}$, Chia-Chih Alex Tseng MD \\ ${ }^{1}$ Department of Anesthesiology, National Cheng Kung University Hospital, College of Medicine, National Cheng Kung University, Tainan, Taiwa \\ ${ }^{2}$ Department of Public Health, National Cheng Kung University Hospital, College of Medicine, Tainan, Taiwan \\ ${ }^{3}$ Department of Anesthesiology, Ditmanson Medical Foundation Chia-Yi Christian Hospital, Chia-Yi, Taiwan
}

\section{Introduction}

Intubation difficulty is an important issue in daily clinical practice for anesthesiologists. ${ }^{1}$ Intubation difficulty scale (IDS) with 7 factors was introduced in 1997.2 It was cited by more than 200 papers but there has been no estimation on relative impacts of time for each. This study aims to quantify the time required to tackle each factor of IDS.

\section{Materials and Methods}

After approval from the IRB, we collected written informed consent from each patient (CYCH IRB: 097028). Preoperatively, a complete medical history related to tracheal intubation (TI) was obtained from every adult patient that would receive an operation and TI under direct laryngoscopy with a \#3 Macintosh blade. After induction, the anesthetists recorded the direct view score according to the 7 IDS factors. With a stop watch, a research assistant independently recorded the duration of each attempt until a successful intubation and sum as intubation time(seconds). Multiple linear regression and mixed effects models were used to determine the relative time impact of each factor.
Intubation Difficulty Scale

\begin{tabular}{|c|c|}
\hline Parameter & Score \\
\hline Number of Attempts $>1$ & $\mathrm{~N}_{1}$ \\
\hline Number of Operators $>1$ & $\mathbf{N}_{2}$ \\
\hline $\begin{array}{l}\text { Number of Alternative } \\
\text { Techniques }\end{array}$ & $\mathbf{N}_{3}$ \\
\hline Cormack Grade - 1 & $\mathbf{N}_{\mathbf{4}}$ \\
\hline Lifting Force Required & \\
\hline $\begin{array}{r}\text { Normal } \\
\text { Increased }\end{array}$ & $\begin{array}{l}N_{5}=0 \\
N_{5}=1\end{array}$ \\
\hline Laryngeal Pressure & \\
\hline $\begin{array}{l}\text { Not applied } \\
\text { Annlied }\end{array}$ & $\begin{array}{l}N_{6}=0 \\
N_{N}=1\end{array}$ \\
\hline $\begin{array}{r}\text { Vocal Cord Mobility } \\
\text { Abduction } \\
\text { Adduction }\end{array}$ & $\begin{array}{l}N_{7}=0 \\
N_{7}=1\end{array}$ \\
\hline $\begin{array}{l}\text { TOTAL: IDS = SUM OF } \\
\text { SCORES }\end{array}$ & $\mathrm{N}_{1}-\mathrm{N}_{7}$ \\
\hline
\end{tabular}

Table 1. Demographic and clinical characteristics of participants before surgery

\begin{tabular}{ll} 
& $\mathrm{N}=1095$ \\
\hline Age (years) & $54.3 \pm 15.0$ \\
Body mass index $\left(\mathrm{Kg} / \mathrm{m}^{2}\right)$ & $26.7 \pm 6.6$ \\
Female $\%$ ) & $715(65.3)$ \\
American Society of & \\
Anesthesiologists & \\
Score 1 & $197(18.0)$ \\
Score 2 & $845(77.2)$ \\
Score 3 & $53(4.8)$ \\
Organ-system of surgery & \\
Thyroid & $175(16.0)$ \\
Breast & $160(14.6)$ \\
Cardiovascular & $9(0.8)$ \\
Abdominal & \\
Upper & $123(11.2)$ \\
Lower & $97(8.9)$ \\
Bariatric & $133(12.1)$ \\
Laparoscope & $170(15.5)$ \\
Esophageal & $3(0.3)$ \\
Orthopedic & $121(11.1)$ \\
Spine & $101(9.2)$ \\
Superficial & $3(0.3)$
\end{tabular}

Table 2. Regression coefficients \pm SE (standard error of mean) from construction of multiple linear regression models with the duration of successful intubation (DSI) as the dependent variable and common factors of the IDS (intubation difficult scale) as independent variables.

\begin{tabular}{lcccc} 
& \multicolumn{2}{c}{ Model 1 } & \multicolumn{2}{c}{ Model 2 } \\
& $y=\mathrm{y}=\mathrm{DSI}-15)$ \\
\cline { 2 - 5 } Operative Factor & $\begin{array}{c}\text { multiple } \\
\text { linear } \\
\text { regression } \\
\text { models }\end{array}$ & $\begin{array}{c}\text { mixed } \\
\text { effects } \\
\text { models }\end{array}$ & $\begin{array}{c}\text { multiple linear } \\
\text { regression } \\
\text { models }\end{array}$ & $\begin{array}{c}\text { mixed } \\
\text { effects } \\
\text { models }\end{array}$ \\
\cline { 2 - 5 } Constant & $\beta \pm \mathrm{SE}$ & $\beta \pm \mathrm{SE}$ & $\beta \pm \mathrm{SE}$ & $\beta \pm \mathrm{SE}$ \\
Additional Attempts & $31.1 \pm 1.1$ & $31.3 \pm 1.1$ & $31.4 \pm 1.0$ & $31.6 \pm 1.0$ \\
Additional Operators & $26.2 \pm 3.3$ & $28.2 \pm 3.3$ & $26.0 \pm 3.1$ & $27.7 \pm 3.1$ \\
Alternative & $11.4 \pm 3.8$ & $6.9 \pm 3.6$ & $11.3 \pm 3.6$ & $6.7 \pm 3.4$ \\
Techniques & $7.9 \pm 1.2$ & $8.0 \pm 1.2$ & $7.5 \pm 1.1$ & $7.5 \pm 1.1$ \\
Increased lift force & $15.2 \pm 0.6$ & $15.6 \pm 0.9$ & $2.6 \pm 0.5$ & $2.9 \pm 0.8$ \\
$\begin{array}{l}\text { External laryngeal } \\
\text { pressure }\end{array}$ & $4.9 \pm 0.9$ & $5.2 \pm 0.9$ & $3.8 \pm 0.8$ & $4.0 \pm 0.8$ \\
Cormack grade - 1 & $3.5 \pm 0.7$ & $3.1 \pm 0.7$ & $2.7 \pm 0.6$ & $2.5 \pm 0.6$ \\
Vocal cord adduction & - & - & - & - \\
$\mathrm{R}^{2}$ & 0.66 & - & 0.67 & - \\
Residual variance & - & 162.00 & - & 146.48
\end{tabular}

\section{Result}

A total of 1095 patients were collected. The IDS score ranged from 0 to 10 . There were $37.1 \%$ and $1.8 \%$ of them with IDS $=0$ and $>5$, respectively, which were lower than those reported by Adnet, ${ }^{2}$ or, $5.3 \%$. (Figure 1) The mean duration of intubation was $23.9 \pm 21.8$ seconds. The final linear regression equation was as follows: Duration of intubation time in seconds $=15.2+$ 31.1 (no. additional attempts) +26.2 (no. additional operators) +11.4 (no. alternative techniques) +7.9 (intubation with increased lift force) +4.9 (intubation with external laryngeal pressure) +3.5 (Cormack grade - 1). (Table 1) After adjustment for repeated intubations by the same anesthesiologists with mixed effects model, we found the regression coefficients were largely the same, indicating the robustness of this model.

\section{Conclusions}

All 7 factors included in the IDS contribute to the time required for intubation except vocal cord adduction. After more corroboration in different settings, the equation would be useful to predict the required time as a feedback on training sessions of tracheal intubation.

\section{References}

1 Cook TM, Woodall N, Harper J, Benger J, Fourth National Audit P. Major complications of airway management in the UK: results of the Fourth National Audit Project of the Royal College of Anaesthetists and the Difficult Airway Society. Part 2: intensive care and emergency departments. British journal of anaesthesia 2011; 106: 632-42

2 Adnet F, Borron SW, Racine SX, et al. The intubation difficulty scale (IDS): proposal and evaluation of a new score characterizing the complexity of endotracheal intubation Anesthesiology 1997; 87: 1290-7 